\title{
Pengaruh Corporate Governance Index Terhadap Ketepatan Waktu Corporate Internet Reporting (Studi Empiris pada Perusahaan Peserta Corporate Governance Perception Index)
}

\author{
Cahyo Indra Dharmawan ${ }^{1}$, Ihyaul Ulum ${ }^{2}$, Endang Dwi Wahyuni ${ }^{3}$ \\ Universitas Muhammadiyah Malang \\ chaaiiyooindra@gmail.com
}

\begin{abstract}
This study aimed at providing empirical evidence of the influence of corporate governance index on the punctuality of corporate internet reporting in companies registered in the Corporate Governance Perception Index (CGPI) in 2015. Data collection technique used was secondary data in form of CG index (corporate governance) and emails from IICG's official website, www.iicg.org and punctuality data to figure out which companies are implementing corporate internet reporting. The sample in this research was 30 companies registered in CGPI 2015. The analysis method used was descriptive statistic and logistic regression with SPSS software version 21. The result of logistic regression analysis indicated that corporate governance index (CGI) had a significant influence on the punctuality of corporate internet reporting (CIR).
\end{abstract}

Keywords: corporate governance index, corporate governance perception index, corporate internet reporting.

ABSTRAK

Penelitian ini bertujuan untuk memberikan bukti empiris pengaruh corporate governance index terhadap ketepatan waktu corporate internet reporting perusahaan yang terdaftar di Corporate Governance Perception Index (CGPI) tahun 2015. Teknik pengumpulan data yang digunakan adalah menggunakan data sekunder berupa indeks CG (Corporate Governance) pelaporan perusahaan berupa email dari website resmi IICG yaitu www.iicg.org dan data ketepatan waktu untuk mengetahui perusahaan yang menerapkan corporate internet reporting. Sampel dalam penelitian ini sebanyak 30 perusahaan yang terdaftar di CGPI tahun 2015. Metode analisis yang digunakan adalah statistik deskriptif dan regresi logistik dengan software SPSS versi 21. Hasil penelitian dengan regresi logistik menunjukkan bahwa Corporate Governance Index (CGI) berpengaruh signifikan terhadap ketepatan waktu Corporate Internet Reporting (CIR).

Kata kunci: corporate governance index, corporate governance perception index, corporate internet reporting. 


\section{PENDAHULUAN}

Ketepatan waktu dalam penyampaian laporan keuangan perusahaan sangat penting dan memiliki informasi yang bermanfaat untuk pengambilan sebuah keputusan bagi pengguna laporan keuangan Semakin pendek waktu antara akhir periode akuntansi dengan tanggal penyampaian laporan keuangan perusahaan, maka semakin banyak manfaat yang dapat diperoleh dari laporan keuangan tersebut. Ketepatan waktu merupakan komponen penting dari informasi keuangan yang relevan dan meningkat regulasi dan otoritas akuntansi (Abdelsalam dan Street, 2007). Untuk mencapai ketepatan waktu tersebut dibutuhkan sebuah informasi yang akurat dan cepat agar informasi yang diperlukan pengguna laporan keuangan tersebut dapat tersedia secara tepat waktu. Dahulu laporan keuangan dipublikasikan melalui media berupa koran, sekarang pelaku bisnis dapat menggunakan teknologi berupa corporate website untuk mempublikasikan laporan keuangannya. Sehingga pengguna dapat memperoleh informasi lebih cepat dan akurat.

Ketepatan waktu menjadi karakteristik yang penting dari suatu informasi akuntansi ketika tujuan tersebut untuk menyediakan informasi yang digunakan oleh pihak-pihak tertentu seperti investor dalam pengambilan sebuah keputusan (Triestyandhari, 2013). Ketepatan waktu dalam penyampaian informasi laporan keuangan sangat penting karena mempunyai nilai manfaat yang lebih tinggi dalam pengambilan sebuah keputusan di masa yang akan datang dan untuk tercapainya kebutuhan informasi yang dibutuhkan oleh semua pihak. Perusahaan yang dapat melakukan ketepatan waktu CIR harus mempunyai corporate governance yang bagus pula.

Fenomena yang terjadi pada perusahaan besar cenderung melakukan ketepatan waktu CIR dibandingkan perusahaan kecil (Kusrinanti, 2012). Keputusan Ketua Bapepam dan Peraturan Laporan Keuangan No. Kep346/BL/2011 nomor X.K.2 tanggal 5 juli, menyatakan bahwa laporan keuangan tahunan wajib disampaikan kepada Bapepam dan Laporan Keuangan yang diumumkan kepada masyarakat paling lama 3 (tiga) bulan atau 90 hari setelah tahun buku berakhir pada saat yang bersamaan dengan tersedianya laporan tahunan bagi pemegang saham. Terlambatnya pelaporan keuangan menyebabkan informasi tersebut kehilangan relevansinya.

Beberapa penelitian telah dilakukan untuk menguji ketepatan waktu pelaporan perusahaan dengan berbagai faktor yang mempengaruhinya. Kusrinanti (2012) menguji pengaruh CG dan karakteristik perusahaan terhadap ketepatan waktu CIR pada perusahaan yang terdaftar di BEI. Berdasarkan hasil uji regresi logistik didapatkan hasil yang menyatakan bahwa terdapat hubungan yang signifikan antara ukuran perusahaan, jenis, profitabilitas, dan penerbitan saham terhadap ketepatan waktu CIR. Variabel lain seperti leverage, likuiditas, struktur 
kepemilikan dan jumlah dewan komisaris tidak berpengaruh signifikan terhadap ketepatan waktu CIR.

Penelitian terbaru dilakukan oleh Widodo (2015) meneliti peran CGPI serta ukuran perusahaan terhadap kinerja keuangan perusahaan pada hasil survei the Indonesian institute for corporate governance (IICG) periode 2010-2012. Hasilnya variabel CGPI berpengaruh signifikan terhadap kinerja keuangan. Dengan demikian besar kecilnya CGPI dapat mempengaruhi besar kecilnya kinerja keuangan. Variabel ukuran perusahaan tidak berpengaruh terhadap kinerja keuangan. Dengan demikian, besar kecilnya ukuran perusahaan tidak dapat mempengaruhi besar kecilnya kinerja keuangan.

Dari uraian diatas peneliti tertarik untuk melakukan penelitian pada perusahaan peserta CGPI. Penelitian ini mengukur pengaruh corporate governance index terhadap ketepatan waktu CIR pada perusahaan peserta CGPI. Penelitian ini menggunakan sampel yang mengacu pada penelitian Widodo (2015). Perusahaan peserta CGPI berupa perusahaan yang masuk dalam indonesia most trusted companies 2016 dan menerapkan corporate internet reporting. Penelitian ini menjadi penting untuk dihasilkan karena di era modern kini dengan teknologi berupa internet, sebagian besar perusahaan mulai mendapatkan keuntungan untuk memenuhi berbagai macam kebutuhan informasi yang dibutuhkan semua pihak, khususnya pihak eksternal untuk dapat mencapai target dan mempertahankan kesuksesan usaha dan sebagai pembuatan keputusan di masa mendatang. Penelitian ini bertujuan untuk menguji dan mengetahui pengaruh corporate governance index terhadap ketepatan waktu CIR pada perusahaan peserta CGPI.

\section{PERUMUSAN HIPOTESIS}

\section{Pengaruh Corporate Governance Index terhadap Ketepatan Waktu Corporate Internet Reporting}

Penerapan GCG yang baik dapat meningkatkan nilai perusahaan karena mengurangi resiko perusahaan dari keputusan pihak manajemen yang cenderung mengutamakan kepentingan pribadi. Ketepatan waktu merupakan elemen yang paling penting dari informasi keuangan untuk profesi akuntansi (Soltani, 2002). Untuk mewujudkan hal tersebut diperlukan informasi yang akurat dan cepat agar pelaporan keuangan dapat tersedia secara tepat waktu dan dapat bermanfaat bagi pengguna laporan keuangan. Informasi yang tepat waktu akan mempengaruhi kemampuan manajemen dalam merespon setiap kejadian atau permasalahan, maka akan menyebabkan informasi tersebut kehilangan nilainya dalam mempengaruhi kualitas pengambilan keputusan. Informasi yang disajikan tepat waktu, akan mendukung manajer menghadapi ketidakpastian yang terjadi di lingkungan kerja mereka (Septriana, 2010). 
Pelaporan perusahaan melalui internet mampu untuk mendistribusikan lebih cepat dan tepat waktu serta lebih transparansi terhadap semua pihak yang membutuhkan. Laporan keuangan yang didistribusikan melalui internet lebih cepat daripada yang biasanya dicetak melalui media.

Indeks corporate governance merupakan petunjuk atau istilah penting yang berupa angka dalam prosentase untuk menggambarkan informasi sebagai tolak ukur (benchmarking). Corporate Governance Index yang tinggi merupakan alat penjamin bagi investor maupun para pengguna laporan keuangan bahwa suatu informasi memiliki manfaat untuk pengambilan sebuah keputusan di masa mendatang. Investor menilai perusahaan dengan Corporate Governance Index tinggi mampu menjamin ketepatan waktu pelaporan perusahaan yang cepat dan akurat. Sedangkan perusahaan dengan nilai corporate governance index yang rendah akan sulit untuk melakukan ketepatan waktu pelaporan perusahaan sehingga menyebabkan terlambatnya informasi yang dibutuhkan dan tidak akan bermanfaat untuk pengambilan sebuah keputusan di masa mendatang.

Berdasar argumen di atas, maka rumusan hipotesis pertama sebagai berikut:

\section{H1: Corporate Governance Index berpengaruh terhadap ketepatan waktu CIR.}

\section{Gambar 1. Kerangka Pemikiran}

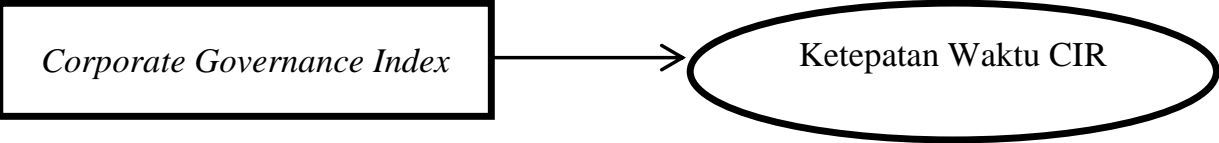

\section{METODE}

Berdasarkan jenisnya penelitian yang dilakukan ini berupa penelitian asosiatif dan dengan penelitian kuantitatif. Variabel-variabel yang diteliti adalah ketepatan waktu CIR sebagai variable dependennya. Variabel indepedennya adalah corporate governance index.

Penelitian ini menggunakan populasi perusahaan yang terdaftar sebagai peserta CGPI tahun 2015 serta terdaftar di BEI. Pemilihan tahun 2015 didasarkan pada tahun terbaru dalam riset CGPI.

Tabel 1. Distribusi Penyampaian Pelaporan Keuangan Perusahaan Pada Periode Penelitian

\begin{tabular}{lcc}
\hline Kategori Perusahaan & Jumlah & Persentase \\
\hline Perusahaan Tepat Waktu & 12 & $40 \%$ \\
Perusahaan Tidak Tepat Waktu & 18 & $60 \%$ \\
\hline
\end{tabular}

Tabel 1, diatas menunjukka bahwa jumlah perusahaan yang melakukan pelaporan keuangan perusahaan melalui internet pada tahun 2015 tergolong tidak tepat waktu. Jumlah sampel perusahaan yang terdaftar di CGPI tahun 2015 adalah 
sebanyak 30 perusahaan. Hanya 12 perusahaan yang melaporkan kondisi perusahaannya secara tepat waktu melalui internet.

Ketepatan waktu corporate internet reporting disini diukur dengan secara nominal dengan menggunakan variabel dummy. Perusahaan yang melaporkan informasi keuangannya di internet $\leq 90$ hari diberi kode 1 , sedangkan perusahaan yang melaporkan informasi keuangannya di internet $>90$ hari diberi kode 0 . Informasi ketepat waktuan CIR didapat dari situs www.idx.co.id_atau melalui website perusahaan.

Variabel ini diukur dengan skor GCG, yakni berupa CGPI yang dikeluarkan oleh lembaga resmi di Indonesia, yaitu The Indonesian Institute for Corporate Governance (IICG). Penilaian CGPI 2015 mencakup 13 aspek penerapan GCG dalam perspektif keberlanjutan di perusahaan. Aspek-aspek tersebut merupakan hasil pengembangan dari CGPI sebelumnya dan dimutakhirkan sesuai dengan relevansi tema CGPI 2015. Keterlibatan organ perusahaan (Dewan Komisaris dan Direksi) memiliki peranan yang penting dalam setiap aspek yang dikembangkan. Bagi peserta yang berasal dari lembaga keuangan syariah, keterlibatan organ perusahaan juga mencakup peran dari Dewan Pengawas Syariah. 13 aspek tersebut meliputi: Komitmen, Transparansi, Akuntabilitas, Responsibilitas, Independensi, Keadilan, Kepemimpinan, Kapabilitas, Strategi, Risiko, Etika, Budaya, dan Keberlanjutan.

Variabel independen dalam penelitian ini berupa skor Good Corporate Governance (GCG) atau Corporate Governance Index yang diperoleh dari IICG. Skor GCG dalam penelitian ini adalah 30 perusahaan peserta CGPI tahun 2015 yang diterbitkan oleh majalah SWA edisi 27/Desember/2016 dalam Indonesian Most Trusted Companies 2016 yang didasarkan pada nilai Corporate Governance Index pada tahun sebelumnya dan pada laporan perusahaan yang menampilkan skor Corporate Governance Index. Skor penilaian meliputi 4 sebaran bobot yakni: self-assessment sebesar (30\%), kelengkapan dokumen sebesar (26\%), penyusunan makalah sebesar (15\%), dan observasi sebesar (29\%). Total skor tersebut yang akan menjadi penilaian.

Jenis data dalam penelitian ini adalah data sekunder. Data sekunder yang digunakan dalam penelitian ini berupa laporan keuangan tahunan yang dihasilkan oleh perusahaan yang terdaftar sebagai Peserta CGPI tahun 2015. Laporan keuangan ini diperoleh dari website IICG (www.iicg.org) dan website perusahaan. Sedangkan untuk skor Corporate Governance Index diperoleh melalui website IICG (www.iicg.org), Majalah Digital SWA (www.swa.co.id), dan beberapa laporan keuangan tahunan perusahaan yang menampilkan Corporate Governance Index. Sedangkan sumber data dari data Eksternal yang bersifat Kuantitatif dan Kualitatif. Pengumpulan data dalam penelitian ini dilakukan dengan cara Observasi website perusahaan dan Laporan GCG berupa skor CGI dari dokumen yang diperoleh dari majalah SWA edisi 27 tahun 2016. 
Teknik analisis data pada penelitian ini menggunakan Model Analisis Regresi Logistik dengan menggunakan SPSS 21. Sebelumnya, data yang terkumpul akan dianalisis secara bertahap dengan pertama dilakukan pengujian statistik deskriptif. Yakni Kualitatif dalam bentuk uraian, dan Kuantitatif dalam bentuk perhitungan. Dalam Pengujian hipotesis dilakukan dengan analisis mulitivariat menggunakan regresi logistik. Regresi logistik dipilih dalam penelitian ini dikarenakan variabel dependen dalam penelitian ini berupa variabel dummy. Pengujian dilakukan pada tingkat signifikansi $(\alpha)$ adalah (5\%) lima persen. Model regresi logistik yang digunakan adalah:

$$
\text { LnCIRT } 1-C I R T=\alpha+\beta \mathrm{CGI}+e
$$

Keterangan :

LnCIRT1-CIR : Dummy variabel, kategori 1 perusahaan yang tepat waktu dalam penerapan CIR, kategori 0 untuk yang tidak tepat waktu.

a : Konstanta

CGI : Corporate Governance Index

e : Kesalahan residual

\section{HASIL DAN PEMBAHASAN}

Populasi dalam penelitian ini merupakan perusahaan yang terdaftar sebagai peserta CGPI tahun 2015 serta terdaftar di BEI. Terdapat sebanyak 30 perusahaan dalam peserta CGPI pada tahun 2015.

Hasil analisis deskriptif ditunjukkan dalam tabel 2 berikut ini:

Tabel 2. Analisis statistik deskriptif

\begin{tabular}{lrrrrrrr}
\hline & N & Range & Minimum & Maximum & Mean & Std. Deviation & Variance \\
\hline CGPI & 30 & 21.37 & 71.93 & 93.30 & 82.2357 & 5.98021 & 35.763 \\
Valid N (listwise) & 30 & & & & & & \\
\hline
\end{tabular}

Tabel statistik deskriptif di atas menunjukkan jumlah sampel dalam penelitian ini adalah 30. Dari 30 data tersebut dapat diketahui nilai minimum dari ukuran perusahaan dilihat dari CGPI adalah 71,93 yang dimiliki oleh PT. Mandiri Manajemen Investasi, sedangkan nilai maksimum didapat 93,30 yang dimiliki oleh PT. Bank Mandiri (Persero) Tbk.

Rata-rata perusahaan yang dilihat dengan CGPI ini sudah baik karena memiliki nilai 82,2357. Berdasarkan data di atas semua variabel memiliki nilai standar deviasi lebih kecil dari nilai mean. Hal ini menunjukan secara garis besar data memiliki variance yang relatif kecil sehingga sebaran data relatif sama/stabil.

\section{Analisis Regresi Logistik}

Pengujian dilakukan dengan membandingkan nilai antara -2 Log Likelihood (2LL) pada awal (Block Number $=0$ ) dengan nilai -2 Log Likelihood $(-2 L L)$ pada 
akhir (Block Number $=1)$. Statistik -2LL dapat digunakan untuk menentukan jika variabel bebas apakah secara signfikan memperbaiki model (Ghozali, 2006). Nilai -2LL awal adalah sebesar 20,338. Setelah dimasukkan kedelapan variabel independen, maka nilai -2LL akhir menjadi 0,000.

\begin{tabular}{|c|c|c|c|c|}
\hline \multicolumn{5}{|c|}{ Iteration History $^{\mathbf{a}, \mathbf{b}, \mathbf{c}, \mathbf{d}}$} \\
\hline \multicolumn{2}{|c|}{ Iteration } & \multirow{2}{*}{$\begin{array}{c}-2 \mathrm{Log} \\
\text { likelihood }\end{array}$} & \multicolumn{2}{|c|}{ Coefficients } \\
\hline & & & Constant & CGPI \\
\hline \multirow{20}{*}{ Step 1} & 1 & 20.338 & -21.299 & .254 \\
\hline & 2 & 12.772 & -41.693 & .495 \\
\hline & 3 & 7.029 & -75.386 & .892 \\
\hline & 4 & 3.546 & -122.719 & 1.450 \\
\hline & 5 & 1.653 & -184.418 & 2.177 \\
\hline & 6 & .693 & -261.404 & 3.085 \\
\hline & 7 & .271 & -348.441 & 4.112 \\
\hline & 8 & .103 & -440.272 & 5.195 \\
\hline & 9 & .039 & -534.727 & 6.309 \\
\hline & 10 & .015 & -631.034 & 7.446 \\
\hline & 11 & .005 & -728.818 & 8.600 \\
\hline & 12 & .002 & -827.817 & 9.768 \\
\hline & 13 & .001 & -927.813 & 10.948 \\
\hline & 14 & .000 & -1028.608 & 12.138 \\
\hline & 15 & .000 & -1130.033 & 13.335 \\
\hline & 16 & .000 & -1231.944 & 14.538 \\
\hline & 17 & .000 & -1334.225 & 15.745 \\
\hline & 18 & .000 & -1436.782 & 16.955 \\
\hline & 19 & .000 & -1539.545 & 18.168 \\
\hline & 20 & .000 & -1642.459 & 19.383 \\
\hline
\end{tabular}

a. Method: Enter

b. Constant is included in the model.

c. Initial -2 Log Likelihood: 40.381

d. Estimation terminated at iteration number 20 because maximum iterations has been reached. Final solution cannot be found.

Tabel 4. Omnibus

\begin{tabular}{|c|c|c|c|c|}
\hline & & Chi-square & $\mathrm{df}$ & Sig. \\
\hline \multirow{3}{*}{ Step 1} & Step & 40.381 & 1 & .000 \\
\hline & Block & 40.381 & 1 & .000 \\
\hline & Model & 40.381 & 1 & .000 \\
\hline
\end{tabular}

H1 = minimal ada satu variabel yang signifikan mempengaruhi variabel y nya. 
Tabel 5. Ringkasan Model

\begin{tabular}{lccc}
\hline Step & $\begin{array}{c}-2 \text { Log } \\
\text { likelihood }\end{array}$ & $\begin{array}{c}\text { Cox \& Snell R } \\
\text { Square }\end{array}$ & $\begin{array}{c}\text { Nagelkerke R } \\
\text { Square }\end{array}$ \\
\hline 1 & $.000^{\mathrm{a}}$ & .740 & 1.000 \\
\hline a. Estimation terminated at iteration number 20 because \\
maximum iterations has been reached. Final solution cannot \\
be found.
\end{tabular}

Tabel diatas menunjukkan bahwa nilai Cox dan Snell R Squaresebesar 0,740 dan Nagelkerke R Squarebernilai 1,000. Hal ini berarti variabilitas variabel dependen dapat dijelaskan oleh variabilitas variabel independen sebesar 1,000 atau $100 \%$.

Tabel 6. Hosmer dan Lemeshow

\begin{tabular}{lrrr}
\hline Step & Chi-square & df & Sig. \\
\hline 1 & .000 & 7 & 1.000 \\
\hline
\end{tabular}

Model dikatakan mampu memprediksi nilai observasi karena cocok dengan data observasinya apabila nilaiHosmer and Lemeshow Goodness of fit test $>0,05$ (Ghozali,2006). Dari hasilnya, nilai signifikansi lebih besar dari 0,05 maka model dapat disimpulkan mampu memprediksi nilainya karena model dikatakan FIT atau berpengaruh.

Tabel 7. Klasifikasi

\begin{tabular}{lllrrr}
\hline & Observed & \multicolumn{3}{c}{ Predicted } \\
& & \multicolumn{2}{c}{ KetepatanWaktu } & Percentage \\
& & $\begin{array}{c}\text { tidak tepat } \\
\text { waktu }\end{array}$ & $\begin{array}{c}\text { tepat } \\
\text { waktu }\end{array}$ & Correct \\
\hline \multirow{3}{*}{ Step 1 } & Ketepatan & tidak tepat waktu & 18 & 0 & 100.0 \\
& Waktu & tepat waktu & 0 & 12 & 100.0 \\
& Overall Percentage & & & 100.0 \\
\hline
\end{tabular}

a. The cut value is .500

Berdasarkan tabel diatas, jumlah sampel yang tidak tepat waktu 18 perusahaan. Jumlah sampel yang tepat waktu 12 perusahaan. Dalam interpretasi regresi logistik dengan SPSS memberikan nilai overall percentage sebesar $(18+12) / 30=100 \%$.

Tabel 8. Persamaan Variabel

\begin{tabular}{|c|c|c|c|c|c|c|c|}
\hline & & B & S.E. & Sig. & $\operatorname{Exp}(B)$ & $95 \%$ C.I.f & $\operatorname{EXP}(B)$ \\
\hline & & & & & & Lower & Upper \\
\hline \multirow{2}{*}{ Step $1^{\mathrm{a}}$} & CGPI & 19.383 & 2038.113 & .992 & 261754290.899 & .000 & . \\
\hline & Constant & -1642.459 & 172674.751 & .992 & .000 & & \\
\hline
\end{tabular}

Tabel diatas merupakan persamaan variabel dengan nilai sig. 0,992 yang artinya menerima H0 karena > 0,05. Sehingga dapat dikatakan bahwa CGPI TIDAK memberikan pengaruh parsial yang signifikan terhadap Ketepatan Waktu CIR dengan nilai koefisien pengaruh sebesar 19,383. 
Besarnya pengaruh ditunjukkan dengan nilai $\operatorname{Exp}(B)$. Variabel independen (kode 1) bernilai positif dengan nilai $\log 19,383$, maka CGPI mempunyai hubungan positif terhadap ketepatan waktu CIR. Sehingga CGPI berpengaruh positif terhadap ketepatan waktu CIR.

\section{Pembahasan}

Hasil pengujian regresi logistik pada penelitian ini menunjukkan variabel Corporate Governance Index berpengaruh positif terhadap ketepatan waktu CIR dengan nilai signifikansi < dari 0,05 pada tabel omnibus dan nilai signifikansi > dari 0,05 pada tabel hosmer dan lemeshow. Maka hasil ini menerima logika yang menyatakan bahwa Corporate Governance Index mempengaruhi ketepatan waktu CIR.

Hasil ini membuktikan bahwa besar kecilnya total skor CGI mempengaruhi ketepatan waktu CIR. Semakin besar nilai skornya maka perusahaan tersebut cenderung semakin tepat waktu dalam menyampaikan laporan keuangan perusahaannya. Dan sebaliknya jika nilai skornya rendah maka perusahaan tersebut cenderung terlambat dalam menyampaikan laporan keuangan perusahaannya.

Hasil penelitian ini sesuai dengan penelitian yang dilakukan oleh Kusrinanti (2012) dan Widodo (2015) yang menyatakan bahwa terdapat banyak faktor-faktor yang mempengaruhi ketepatan waktu CIR dan besar kecilnya total skor CGI mempengaruhi variabel-variabel lain didalamnya.

Hubungan Corporate Governance Index berpengaruh terhadap ketepatan waktu CIR adalah adanya upaya untuk mendorong dan menuntut perusahaan agar melakukan ketepatan waktu karena tekanan dari berbagai pihak misalnya investor, yakni untuk mengungkapkan pelaporan perusahaannya secara tepat waktu agar digunakan untuk pengambilan sebuah keputusan dimasa yang akan datang.

Dengan adanya transparansi dan responsibilitas perusahaan dalam Corporate Governance Index yang menunjukkan tanggungjawab perusahaan dalam menyampaikan berbagai informasi tentang perusahaan secara tepat waktu dan akurat. Serta merupakan strategi dalam menerapkan CIR untuk berkompetisi dengan perusahaan pesaing dalam era modern ini.

Perusahaan dengan GCG yang baik akan cenderung melakukan ketepatan waktu CIR sehingga perusahaan tersebut dapat mengurangi resiko perusahaan dan meningkatkan kepercayaan para investor. Corporate governance Index yang tinggi dengan menerapkan ketepatan waktu memiliki manfaat untuk pengambilan sebuah keputusan di masa mendatang. Berdasarkan teori agensi, manajer (agen) bekerja secara efisien dan efektif sehingga laporan keuangan perusahaan yang dibuat sebagai bentuk pertanggungjawaban kepada pemilik perusahaan dan mampu meminimalkan risiko. 


\section{KESIMPULAN}

Penelitian ini bertujuan untuk menguji dan mengetahui pengaruh corporate governance index terhadap ketepatan waktu CIR pada perusahaan peserta CGPI tahun 2015. Data sampel sebanyak 30 perusahaan dianalisis menggunakan aplikasi SPSS ver 21.

Hasil penelitian ini membuktikan bahwa variabel Corporate Governance Index (CGI) berpengaruh signifikan terhadap ketepatan waktu CIR. Dengan demikian hipotesis pertama yang menyatakan bahwa Corporate Governance Index (CGI) berpengaruh terhadap ketepatan waktu CIR terbukti (H1 diterima). Hal tersebut mengindikasikan bahwa besar kecilnya Corporate Governance Index (CGI) dapat mempengaruhi ketepatan waktu CIR.

\section{SARAN}

Saran yang didasarkan pada penelitian ini dengan terbatasnya alat untuk mengukur nilai penerapan CG di Indonesia, selain menggunakan corporate governcance perception index (CGPI) yang dikeluarkan oleh IICG (The Indonesian Institute of Corporate Governance) terdapat satu alat ukur yang dikeluarkan oleh IICD (The Indonesian Institute of Corporate Directorship). Peneliti selanjutnya bisa menggunakan alat ukur tersebut untuk mengukur dan menilai efektivitas penerapan CG.

\section{DAFTAR PUSTAKA}

Abdelsalam, Omneya H, dan Donna L. Street. 2007. Corporate governance and the timeliness of corporate internet reporting by U.K. listed companies. Journal of International Accounting, Auditing and Taxation 16 (2007) 111130.

Corporate Governance Perception Index. 2015. www.iicg.org.

Ghozali, Imam. 2006. Analisis Multivariate dengan Program SPSS. Semarang: Badan Penerbit Universitas Diponegoro.

Keputusan Ketua Bapepam dan LK No. Kep-346/BL/2011 Peraturan No. X.K.2.

Kusrinanti, Maria Aditya dan M. Syafruddin. 2012. Pengaruh Corporate Governance terhadap Ketepatan Waktu Corporate Internet Reporting pada Perusahaan yang Terdaftar di Bursa Efek Indonesia. Simposium Nasional Akuntansi XV, Banjarmasin.

Laporan Keuangan. BEI. www.idx.co.id.

Majalah Digital SWA. 2016. www.swa.co.id. 
Septriana, Ira. 2010.Analisis Faktor-Faktor yang Berpengaruh terhadap Ketepatan Waktu Pelaporan Keuangan Perusahaan BUMN di Indonesia. Jurnal Manajemen dan Akuntansi. Vol. 10, No. 1, hal. 97-117.

Soltani, B. 2002. Timeliness of Coporate and Audit Reports: Some Empirical Evidence in the French Context. The International Journal of Accounting, 37 (2): 215-26.

Triestyandhari, Dhita dan Devi. 2013. Pengaruh Corporate Governance dan Karakteristik Perusahaan Terhadap Ketepatan waktu corporate internet reporting. Tidak dipublikasikan.

Widodo, F.A. 2015. Peran Corporate Governance Perception Index serta Ukuran Perusahaan Terhadap Kinerja Keuangan Perusahaan Pada Hasil Survei The Indonesian Institute for Corporate Governance (IICG) Periode 2010-2012. Jurnal Akuntansi. Universitas Dian Nuswantoro Semarang. 